\title{
DDAH gene and cardiovascular risk
}

\author{
Veli-Pekka Valkonena , Tomi-Pekka Tuomainen ${ }^{a}$ and Reijo Laaksonen ${ }^{b}$
}

\begin{abstract}
The crucial role of nitric oxide (NO) for normal endothelial function is well known. In many conditions associated with increased risk of cardiovascular diseases such as hypercholesterolemia, hypertension, abdominal obesity, diabetes and smoking, NO biosynthesis is dysregulated, leading to endothelial dysfunction. The growing evidence from animal and human studies indicates that endogenous inhibitors of endothelial NO synthase such as asymmetric dimethylarginine (ADMA) and $N^{G}$-monomethyl-L-arginine (L-NMMA) are associated with the endothelial dysfunction and potentially regulate NO synthase. The major route of elimination of ADMA is metabolism by the enzymes dimethylarginine dimethylaminohydrolase- 1 and -2 (DDAH). In our recent study 16 men with either low or high plasma ADMA concentrations were screened to identify DDAH polymorphisms that could potentially be associated with increased susceptibility to cardiovascular diseases. In that study a novel functional mutation of DDAH-1 was identified; the mutation carriers had a significantly elevated risk for cardiovascular disease and a tendency to develop hypertension. These results confirmed the clinical role of DDAH enzymes in ADMA metabolism. Furthermore, it is possible that more common variants of DDAH genes contribute more widely to increased cardiovascular risk.
\end{abstract}

Key words: ADMA; DDAH; cardiovascular disease; gene mutation

\section{Introduction}

The development of atherosclerosis is associated with endothelial dysfunction, which is linked closely to various other pathological conditions that predispose to atherosclerosis, including hypercholesterolemia, ${ }^{1,2}$ hypertension, ${ }^{3}$ types 1 and 2 diabetes, ${ }^{4,5}$ hyperhomocyst(e)inemia, ${ }^{6}$ chronic renal failure, ${ }^{7}$ obesity (abdominal), ${ }^{5}$ infection, ${ }^{8}$ aging ${ }^{9}$ and smoking. ${ }^{10} \mathrm{~A}$ major cause of the endothelial dysfunction is decreased bioavailability of nitric oxide (NO), a potent biological vasodilator synthesized in vascular endothelium from L-arginine by the action of endothelial NO synthase (eNOS). Endothelium-derived NO maintains vascular/endothelial functions in various ways. NO is a critical mediator in vasodilation and antithrombotic processes, as well as in growth inhibition and inflammation.

Asymmetric dimethylarginine (ADMA) is one of three known endogenously produced circulating methylarginines (i.e. ADMA, $N^{G}$-monomethyl-L-argi-

\footnotetext{
aThe Research Institute of Public Health, University of Kuopio, Kuopio, Finland; bViikki Drug Discovery Technology Center, University of Helsinki, Finland

Address for correspondence: Veli-Pekka Valkonen, The Research Institute of Public Health, University of Kuopio, PO Box 1627, 70211 Kuopio, Finland. Fax: +358 17162936 ; Tel: +358442852121; E-mail: Velipekka.Valkonen@uku.fi
}

nine (L-NMMA) and symmetrically methylated $N^{G}$,

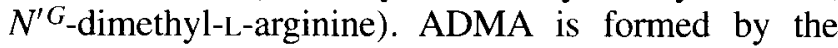
action of protein arginine methyltransferases that methylate arginine residues in proteins and after which free ADMA is released. ${ }^{11,12}$ ADMA and L-NMMA can competitively inhibit NO elaboration by displacing L-arginine from NO synthase (NOS). ${ }^{13,14}$ The amount of methylarginines is related to overall metabolic activity and the protein turnover rate of cells. Although methylarginines are excreted partly by the kidneys, ${ }^{13}$ the major route of elimination of ADMA in humans is metabolism by the dimethylarginine dimethylaminohydrolase (DDAH) enzymes. ${ }^{15-17}$ Inhibition of DDAH leads to the accumulation of ADMA ${ }^{16,18,19}$ and consequently to inhibition of NO-mediated endotheliumdependent relaxation of blood vessels.

\section{ADMA and cardiovascular diseases}

Several studies have shown that elevated ADMA levels are present in patients with different types of coronary heart disease. The potential role of ADMA in angina pectoris has been evaluated by Piatti and co-workers, who reported ADMA levels to be higher in patients with cardiac syndrome $\mathrm{X}$ (angina pectoris with normal coronary arteriograms) than in controls. ${ }^{20}$ According to Japanese data in patients with vasospastic angina there is an increased ADMA concentration 
that relates to a decrease in NO concentrations in the coronary circulation. ${ }^{21}$ Together with other evidence $^{22,23}$ showing the endothelial dysfunction to be one essential phenomenon in the development of clinically significant coronary artery disease, it seems likely that ADMA could be a potent marker for cardiovascular risk.

In the results of a few prospective studies there has been a clear indication that a raised ADMA level is related to increased cardiovascular events in patients with end-stage renal disease ${ }^{24}$ and in previously healthy middle-aged men. ${ }^{25}$ According to preliminary results from the CARDIAC (Coronary Artery Risk Determination investigating the influence of ADMA Concentration) study, patients with coronary heart disease $(n=816)$ had a higher median ADMA plasma concentration than age and sex matched controls (median 0.91 vs. $0.70 \mu \mathrm{mol} / \mathrm{l} ; p<0.0001$ ). ${ }^{26}$ It is interesting that, in a prospective Chinese study, a high plasma ADMA level independently predicted subsequent cardiovascular adverse events (cardiovascular death, myocardial infarction, and repeated revascularization of a target vessel). ${ }^{27}$

\section{DDAH and cardiovascular diseases}

There are only few published findings concerning variations in human DDAH. However, polymorphisms in other genes potentially related to risk factors for endothelial dysfunction and cardiovascular events have been studied. Reduced NO synthesis has been implicated in the development of atherosclerosis. ${ }^{28}$ For example, there are some functionally important variants of the NOS $3^{29,30}$ that could affect individual vulnerability to atherosclerosis by changing the amount of NO generated by the endothelium. ${ }^{31-34}$ In a British population study, the relationship between G3T polymorphism in exon 7 of the NOS3 gene variant and atherosclerotic coronary artery disease was investigated using two independent case-controlled studies. ${ }^{34}$ The authors reported that homozygosity for a common NOS3 polymorphism (894 G3T) that encodes a Glu298Asp amino acid substitution in eNOS is a risk factor for angiographic coronary artery disease and recent myocardial infarction. In another British study, this NOS3 gene variant did not influence significantly the level of plasma NO end products (nitrate + nitrite) or the risk of ischaemic heart disease in middle-aged British men. ${ }^{35}$

There have been some animal and human studies in which a critical role for DDAH activity in regulating NO synthesis in vivo was demonstrated. In one mouse model, overexpression of DDAH-1 did increase NOS activity in vitro and in vivo. ${ }^{36}$ In the same study, the human DDAH-1 transgenic animals exhibited reduced systolic blood pressure, systemic vascular resistance and cardiac stroke volume. Further evidence that the metabolism of endogenous ADMA and DDAH plays an important role in the regulation of NOS activity was shown in a human study. Vallance and his group found a functional insertion/deletion polymorphism variant in the DDAH-2 enzyme among unrelated individuals. ${ }^{37} \mathrm{~A}$ variant in the core promoter region was associated with increased basal DDAH-2 expression. The prevalence of the variant was about $1 \%$ in the population studied. These studies show that there could be functional variants in DDAH genes and that, when other population samples are studied, it is likely that new functional polymorphisms in genes coding DDAH enzymes will be found, and that these variations in expression or activity of the DDAH enzymes may affect the risk of vascular events (Figure 1). This hypothesis was tested in our recent population study in 1609 middle-aged Finnish men, who were participants in the Kuopio Ischemic Heart Disease Risk Factor Study (KIHD), which is an ongoing population-based study designed to investigate risk factors for cardiovascular diseases, type 2 diabetes and related outcomes in men from eastern Finland. ${ }^{23}$ In this study we identified several variants of DDAH. One variant was found in the DDAH-2 and six variants were observed in the DDAH-1 gene. The identified gene variants were, however, very rare in our study population. We were able to confirm statistical analyses for one DDAH-1 variant. This mutation was found in 13 men. No homozygous mutation carriers were identified. In a logistic regression model adjusting for age, serum triglyceride, hypertension and smoking status, the occurrence of coronary heart disease was over 50 -fold for mutation carriers versus noncarriers. In a risk factor (age, smoking status and body mass index) adjusted model, the mutation carriers had almost a five-fold prevalence of hypertension. Haplotype analysis gave similar results to the above mentioned single mutation analysis. All 13 DDAH mutation carriers were used as probands for a family study of 55 relatives (spouses and siblings). About $50 \%$ of the relatives of the probands were carriers of this mutation. The prevalence of hypertension was almost six-fold higher among the DDAH mutation carriers compared with the noncarriers. There were no significant differences between other cardiovascular diseases in the family study. Plasma ADMA levels were higher in the DDAH-1 mutation carriers compared with the noncarrier relatives.

\section{Conclusions}

There are probably several functional variations in genes coding DDAH enzymes in different populations. Some of them could confer protection against the harmful effects of elevated ADMA and others impair enzyme function causing accumulation of ADMA in cytosol and/or blood. We have recently 


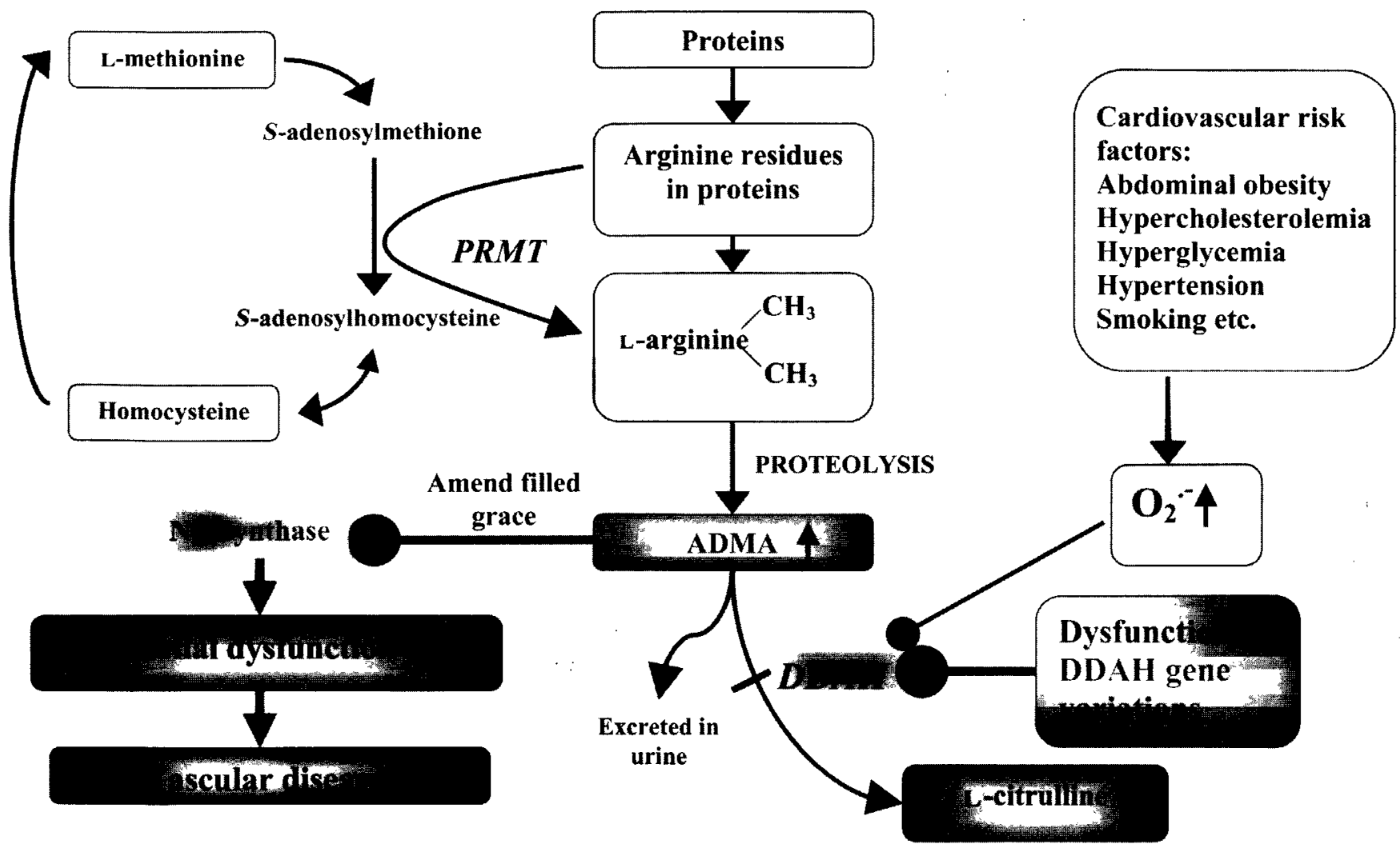

Figure 1 Possible pathways by which variants of the DDAH gene could affect ADMA degradation, increasing susceptibility to cardiovascular diseases.

found a rare variation in the DDAH-1 gene, which is associated with elevated plasma concentrations of ADMA in heterozygous mutation carriers. There was also an increased prevalence of CHD and a tendency to hypertension among individuals with this DDAH-1 mutation. These observations highlight the importance of ADMA as a possible risk factor and emphasize the essential role of DDAH in regulating ADMA levels.

\section{Acknowledgments}

We would like to thank the Centre for Clinical Pharmacology, Division of Medicine, University College of London, UK, the Research Institute of Public Health, University of Kuopio, Finland, and Jurilab Ltd, Kuopio, Finland, for their excellent collaboration.

\section{References}

1 Creager MA, Cooke JP, Mendelsohn ME et al. Impaired vasodilation of forearm resistance vessels in hypercholesterolemic humans. J Clin Invest 1990; 86: 228-34.

2 Chowienczyk PJ, Watts GF, Cockcroft JR, Ritter JM. Impaired endothelium-dependent vasodilation of forearm resistance vessels in hypercholesterolaemia. Lancet 1992; 340: 1430-32.
3 Panza JA, Quyyumi AA, Brush JE, Epstein SE. Abnormal endothelium-dependent vascular relaxation in patients with essential hypertension. N Engl J Med 1990; 323: 22-27.

4 Johnstone MT, Creager SJ, Scales KM, Cusco JA, Lee BK, Creager MA. Impaired nitric oxide-mediated vasodilation in patients with non-insulin-dependent diabetes mellitus. Circulation 1993; 88: 2510-16.

5 Steinberg HO, Chaker H, Leaming R, Johnson A, Brechtel G, Baron AD. Obesity/insulin resistance is associated with endothelial dysfunction. Implications for the syndrome of insulin resistance. J Clin Invest 1996; 97: 2601-10.

6 Woo KS, Chook P, Lolin YI et al. Hyperhomocyst(e)inemia is a risk factor for arterial endothelial dysfunction in humans. Circulation 1997; 96: 2542-44.

7 Kari JA, Donald AE, Vallance DT et al. Physiology and biochemistry of endothelial function in children with chronic renal failure. Kidney Int 1997; 52: 468-72.

8 Fichtlscherer S, Zeiher AM. Endothelial dysfunction in acute coronary syndromes: association with elevated C-reactive protein levels. Ann Med 2000; 32: 515-18.

9 Vita JA, Treasure CB, Nabel EG. Coronary vasomotor response to acetylcholine relates to risk factors for coronary artery disease. Circulation 1990; 81: 491-97.

10 Heitzer T, Just H, Münzel T. Antioxidant vitamin C improves endothelial dysfunction in chronic smokers. Circulation 1996; 94: 6-9.

11 Clarke S. Protein methylation. Curr Opin Cell Biol 1993; 5: 977-83.

12 McBride AE, Silver PA. State of the Arg:protein methylation at arginine comes of age. Cell 2001; 106: 5-8. 
13 Vallance $\mathrm{P}$, Leone A, Calver A, Collier J, Moncada S. Accumulation of an endogenous inhibitor of nitric oxide synthesis in chronic renal failure. Lancet 1992; 339: 572-75.

14 Zelis R, Mason DT, Braunwald E. A comparison ot the effects of vasodilator stimuli on peripheral resistance vessels in normal subjects and in patients with congestive heart failure. $J$ Clin Invest 1968; 47: 960-70.

15 McDermott JR. Studies on the catabolism of $\mathrm{Ng}$ methylarginine, $\mathrm{Ng}, \mathrm{Ng}$-dimethylarginine and $\mathrm{Ng}, \mathrm{Ng}-$ dimethylarginine in the rabbit. Biochem $J 1976 ; 154$ : 179-84.

16 MacAllister RJ, Parry H, Kimoto M et al. Regulation of nitric oxide synthesis by dimethylarginine dimethylaminohydrolase. Br J Pharmacol 1996; 119: 1533-40.

17 Murray-Rust J, Leiper J, McAlister M et al. Structural insights into the hydrolysis of cellular nitric oxide synthase inhibitors by dimethylarginine dimethylaminohydrolase. Nat Struct Biol 2001; 8: 679-83.

18 Ito A, Tsao PS, Adimoolam S, Kimoto M, Ogawa T, Cooke JP. Novel mechanism for endothelial dysfunction. Dysregulation of dimethylarginine dimethylaminohydrolase. Circulation 1999; 99: 3092-95.

19 Ueda S, Kato S, Matsuoka $\mathrm{H}$ et al. Regulation of cytokineinduced nitric oxide synthesis by asymmetric dimethylarginine: role of dimethylarginine dimethylaminohydrolase. Circ Res 2003; 92: 226-33.

20 Piatti PM, Fragasso G, Monti LD. Acute intravenous L-arginine infusion decreases endothelin-1 levels and improves endothelial function in patients with angina pectoris and normal coronary arteriograms: correlation with asymmetric dimethylarginine levels. Circulation 2003; 107: 429-36.

21 Hori T, Matsubara T, Ishibashi $T$ et al. Significance of asymmetric dimethylarginine (ADMA) concentrations during coronary circulation in patients with vasospastic angina. Circ $J$ 2003; 67: 305-11.

22 Gage JE, Hess OM, Murakami T, Ritter M, Grimm J, Krayenbuehl HP. Vasoconstriction of stenotic arteries during dynamic exercise in patients with classic angina pectoris: reversibility by nitroglycerin. Circulation 1986; 73: 865-76.

23 Zeiher AM, Krause T, Schächinger V, Minners J, Moser E. Impaired endothelium-dependent vasodilation of coronary resistance vessels is associated with exercise-induced myocardial ischemia. Circulation 1995; 91: 2345-52.

24 Zoccali C, Bode-Boger S, Mallamaci F et al. Plasma concentration of asymmetrical dimethylarginine and mortality in patients with end-stage renal disease: a prospective study. Lancet 2001; 358: 2113-17.
25 Valkonen V-P, Päivä H, Salonen JT et al. Risk of acute coronary events and serum concentration of asymmetrical dimethylarginine. Lancet 2001; 358: 2127-28.

26 Böger RH, Lenzen $H$, Hanefeld $C$ et al. Asymmetric dimethylarginine: an endogenous inhibitor of NO synthase is a predictor of the risk for coronary heart disease - results of the multicenter CARDIAC study [Abstract]. Circulation 2003; 108(suppl 4): 256-57.

27 Lu TM, Ding YA, Lin SJ, Lee WS, Tai HC. Plasma levels of asymmetrical dimethylarginine and adverse cardiovascular events after percutaneous coronary intervention. Eur Heart J 2003; 24: 1912-19.

28 Cooke JP, Dzau VJ. Nitric oxide synthase: role in the genesis of vascular disease. Annu Rev Med 1997; 48: 489-509.

29 Wang XL, Sim AS, Badenhop RF, McCredie RM, Wilcken DE. A smoking-dependent risk of coronary artery disease associated with a polymorphism of the endothelial nitric oxide synthase gene. Nat Med 1996; 2: 41-45.

30 Hingorani AD, Jia H, Stevens PA, Monteith MS, Brown MJ. A common variant in exon 7 of the endothelial constitutive nitric oxide synthase gene [Abstract]. Clin Sci 1995; 88: 21P.

31 Miyamoto $\mathrm{Y}$, Saito $\mathrm{Y}$, Kajiyama $\mathrm{N}$ et al. Endothelial nitric oxide synthase gene is positively associated with essential hypertension. Hypertension 1998; 32: 3-8.

32 Hibi K, Ishigami T, Tamura $\mathrm{K}$ et al. Endothelial nitric oxide synthase gene polymorphism and acute myocardial infarction. Hypertension 1998; 32: 521-26.

33 Shimasaki Y, Yasue H, Yoshimura $M$ et al. Association of the missense Glu298Asp variant of the endothelial nitric oxide synthase gene with myocardial infarction. $J$ Am Coll Cardiol 1998; 31: 1506-10.

34 Hingorani AD, Liang CF, Fatibene J et al. A common variant of the endothelial nitric oxide synthase Glu298Asp is a major risk factor for coronary artery disease in the UK. Circulation 1999; 100: 1515-20.

35 Jeerooburkhan N, Jones LC, Bujac S et al. Genetic and environmental determinants of plasma nitrogen oxides and risk of ischemic heart disease hypertension. 2001; 38: 1054-61.

36 Dayoub H, Achan V, Adimoolam S et al. Dimethylarginine dimethylaminohydrolase regulates nitric oxide synthesis: genetic and physiological evidence. Circulation 2003; 108: 3042-47.

37 Jones LC, Tran CTL, Leiper JM, Hingorani AD, Vallance P. Common genetic variation in a basal promoter element alters DDAH2 expression in endothelial cells. Biochem Biophy Res Commun 2003; 310: 836-43. 